\section{Case Reports in Oncology}

\title{
Adjuvant Treatment of the Salivary Duct Carcinoma with Her2 Overexpression
}

\author{
Jelena Berendika ${ }^{a}$ Saša Jungića, b Biljana Tubićc, d \\ Gordana Malčić Kecman ${ }^{\mathrm{e}}$ Ivanka Rakita ${ }^{a}$ Zdenka Gojkovića, b

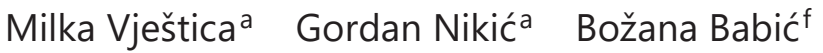 \\ ancology Clinic, University Clinical Centre of the Republic of Srpska, Banja Luka, Bosnia \\ and Herzegovina; ' University of Banjaluka Faculty of Medicine, Banja Luka, Bosnia and \\ Herzegovina; 'Department of Pharmacy, University of Banjaluka Faculty of Medicine, Banja \\ Luka, Bosnia and Herzegovina; ${ }^{\mathrm{d} A g e n c y}$ for Medicines and Medical Devices of Bosnia and

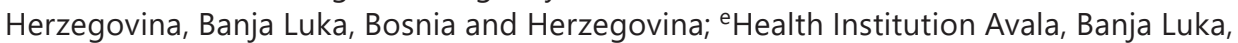 \\ Bosnia and Herzegovina; fPathology Clinic, University Clinical Centre of the Republic of \\ Srpska, Banja Luka, Bosnia and Herzegovina
}

\section{Keywords}

Salivary duct carcinoma - Adjuvant therapy · Trastuzumab

\begin{abstract}
Malignant salivary gland tumors form $11 \%$ of all head and neck tumors. Salivary duct carcinoma (SDC) of the parotid gland is an uncommon and highly aggressive tumor accounting for $2 \%$ of all salivary gland malignancies. The fourth edition of the WHO Classification of Head and Neck Tumors reported global annual incidence of $0.4-2.6 / 100,000$ people. Standard treatment for SDC is wide surgical resection along with lymph node dissection followed by adjuvant radiation therapy. The role of adjuvant chemotherapy is not known. Here, we present a case of an SDC of the parotid gland in a 55-year-old female. She presented with a painless swelling behind her right ear. Surgery was performed, and total right parotidectomy was done along with selective neck dissection (levels II, III, VA). The pathology report concluded that it was a G3 (poorly differentiated) SDC (micropapillary variant) with lymphovascular and perineural invasion. The clinical stage of the disease was T4aN2bM0. Adjuvant therapy consisted of concurrent radiation (TD $66 \mathrm{~Gy})$ and chemotherapy with weekly paclitaxel $\left(45 \mathrm{mg} / \mathrm{m}^{2}\right)$, carboplatin (AUC 1.5), and trastuzumab ( $2 \mathrm{mg} / \mathrm{kg}$; THC) for 6 weeks followed by 4 cycles of THC every 3 weeks. Adjuvant trastuzumab was continued for a total of 1 year. She is still without the evidence of the disease 7 years later. The consensus regarding the use of adjuvant chemotherapy does not exist. Based on all the data that have been presented before, the conclusion is that we need new treatment modalities to improve the outome of this aggressive disease.
\end{abstract}




\section{Introduction}

Malignant salivary gland tumors form $11 \%$ of all head and neck tumors. Salivary duct carcinoma (SDC) of the parotid gland is an uncommon and highly aggressive tumor accounting for $2 \%$ of all salivary gland malignancies. The fourth edition of the WHO Classification of Head and Neck Tumors reported aglobal annualincidence of $0.4-2.6 / 100,000$ people. Patients, mostly aging men,usually present with a painless mass in their face or neck, and some of them have facial paralysis. SDC was defined in the 2005 WHO Classification as "an aggressive adenocarcinoma which resembles high-grade breast ductal carcinoma" [1]. This resemblance led to the study of hormone receptor status and HER2/neu expression [2]. When HER2 positivity is defined by fluorescence or chromogenic in situ hybridization amplification, HER2 positivity is reported to be found in only $15 \%$ to a maximum of $40 \%$ [3-7]. SDCs are androgen receptor positive in 67-97\% cases [7-9]. Standard treatment for SDC is wide surgical resection along with lymph node dissection followed by adjuvant radiation therapy. The role of adjuvant chemotherapy is not known because the incidence of the disease is very low and the are no prospective clinical trials. The survival rate is poor and most patients die within 3 years, with overall survival reported as low as $42 \%$ for stage I disease and $23 \%$ for stage IV disease [10]. There are no standard treatment options for recurrent and metastatic disease. Only 3 cases have been reported in University Clinical Center of the Republic of Srpska in the last 11 years.

\section{Case Report/Case Presentation}

Here, we present a case of an SDC of the parotid gland in a 55-year-old female. She had no history of cancer in her family, and had ECOG PS 0. She presented with a painless swelling behind her right ear. Biopsy was done, and pathology report came as adenocarcinoma. MRI of

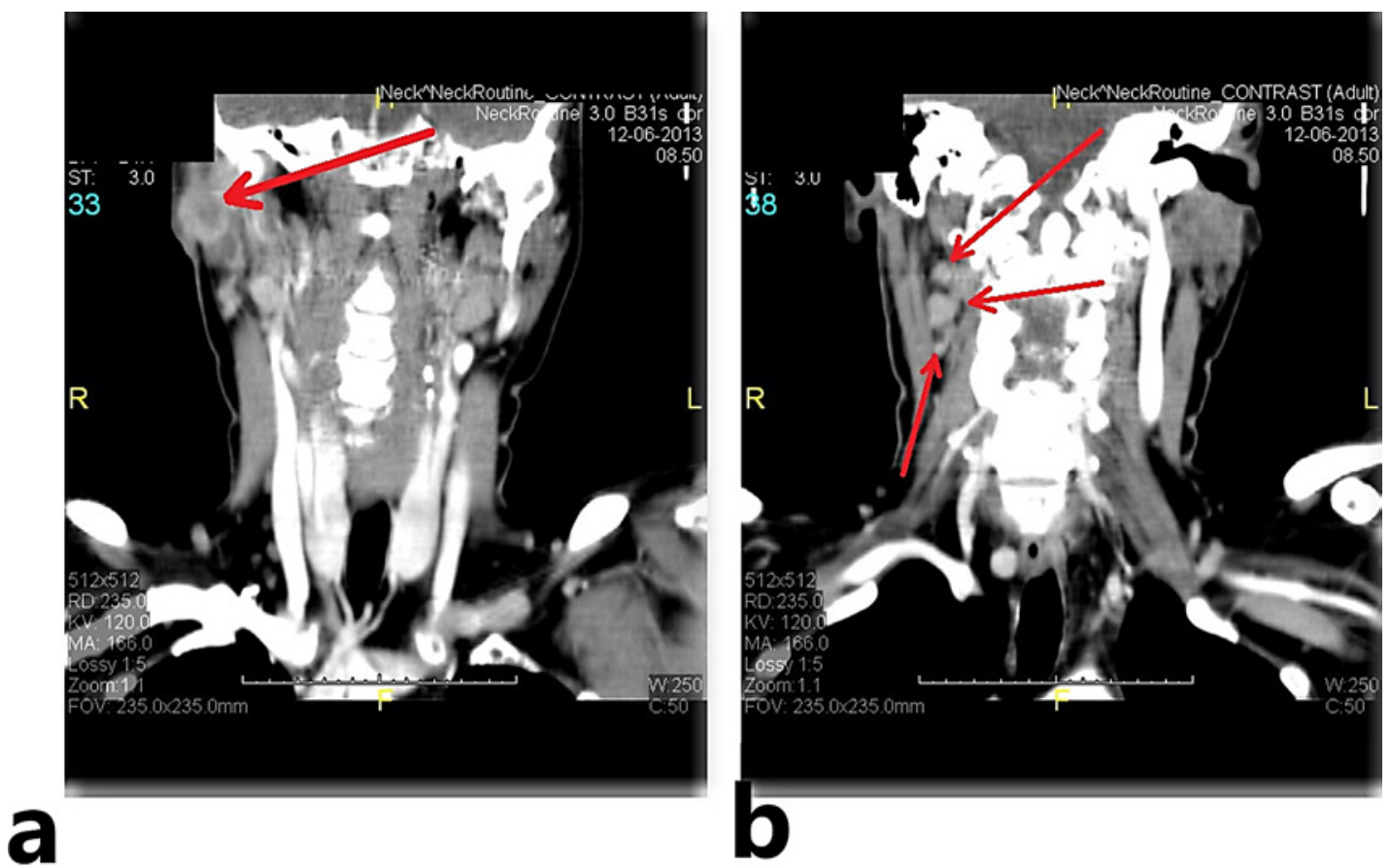

Fig. 1. a Neck CT scan with contrast axial cut, soft tissue window: tumor of the parotid gland. b Neck CT scan with contrast axial cut, sof tissue window: enlarged lymph nodes. 
Fig. 2. Salivary duct carcinoma, micropapillary type. HE. $\times 5$.

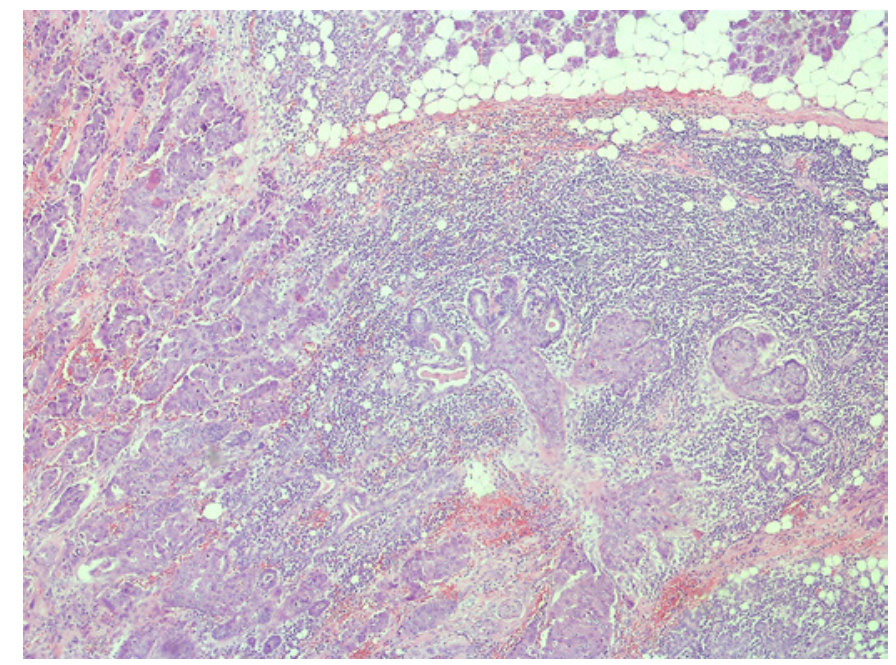

the neck region showed tumor in the parotid gland that took up most of the gland and enlarged lymph nodes in the II, III, and VA group on the right side, shown in Figure 1, and a few enlarged lymph nodes on the opposite side (shorter diameter up to $10 \mathrm{~mm}$ ). Surgery was performed, and total right parotidectomy was done along with selective neck dissection (levels II, III, VA). Pathology report concluded that it was a G3 (poorly differentiated) SDC (micropapillary variant) with lymphovascular and perineural invasion, shown in Figure 2. Three intraparotid lymph nodes were infiltrated with tumor tissue along with cutis, subcutis, and muscle. The number of mitoses was $8-10 / \mathrm{HPF}$, Ki-67 positivity was $65 \%$, and it was not possible to determine resection margins. 11 out of 13 neck lymph nodes were positive for tumor cells with invasion of perinodal tissue and lymphovascular and perineural invasion. Immunohistochemistry was positive for Her 2/neu 3+, EMA, CK (HMW), CEA, AR and GCDFP-15 and negative for S100, ER/PR and TTF1, shown in Figure 3. The clinical stage of the disease was T4aN2bM0. The multidisciplinary tumor board decided that this patient should receive adjuvant therapy. Adjuvant therapy consisted of concurrent radiation (TD 66 Gy) and chemotherapy with weekly paclitaxel (45 mg/m²), carboplatin (AUC 1.5), and trastuzumab (2 mg/kg; THC) for 6 weeks followed by 4 cycles of THC every 3 weeks. Adjuvant trastuzumab was continued for a total of 1 year. She is without the evidence of the disease 7 years later.

\section{Discussion/Conclusion}

SDC is a rare and aggressive type of salivary gland cancer with high morbidity and mortality. NCCN guidelines in 2013, at the time when this patient was diagnosed, recommended adjuvant radiation therapy or adjuvant chemo/radiotherapy and chemotherapy for metastatic disease. NCCN guidelines today recommend the same with the use of trastuzumab for HER2+ disease and androgen receptor therapy for AR+ tumor in a metastatic setting. In February 2013, The Oncologist published a paper about the use of trastuzumab in SDC. A total of 13 patients with SDC and HER2/neu expression were treated with trastuzumab in an adjuvant $(n=8)$ or palliative $(n=5)$ setting. Adjuvant therapy consisted of concurrent radiation and chemotherapy with weekly paclitaxel, carboplatin, and trastuzumab (TCH) for 6 weeks followed by TCH for 12 weeks and trastuzumab alone for 1 year. Palliative treatment for metastatic disease consisted of paclitaxel $\left(175 \mathrm{mg} / \mathrm{m}^{2}\right.$ ) , carboplatin (AUC 5-6), and weekly trastuzumab $(2 \mathrm{mg} / \mathrm{kg}$ ) every 3 weeks for 6 cycles followed by trastuzumab for variable periods of time. $62 \%$ of adjuvant patients $(5 / 8)$ had no evidence of disease more than 


\section{Case Reports in Oncology}
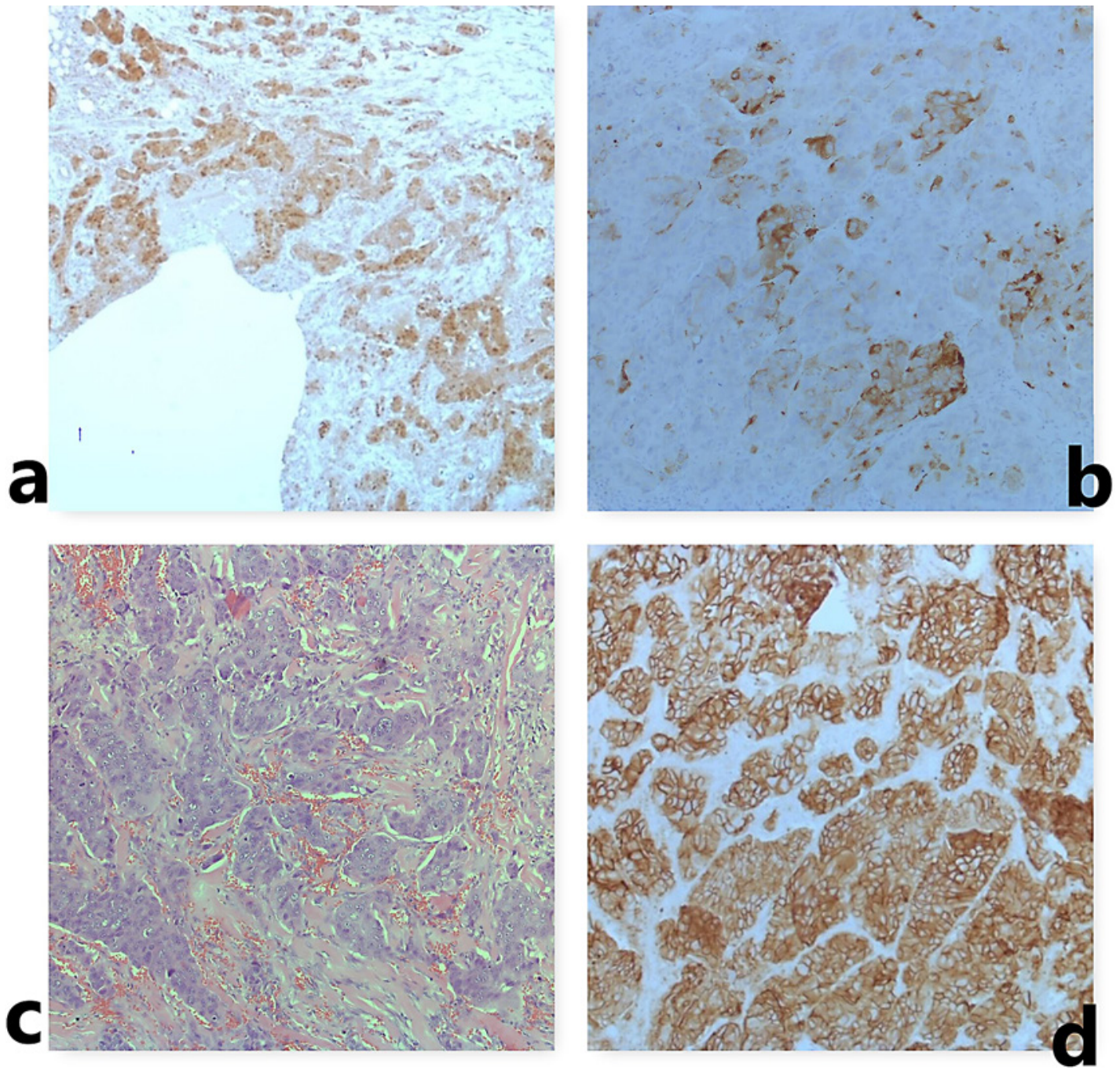

Fig. 3. a ICH, AR focal nuclear staining in tumor cells. $\times 5$. b ICH, GCDFP 15 focal cytoplasm staining in tumor cells. $\times 10$. c Histology grade 3 . HE. $\times 20$. d ICH HER 2, diffuse strong membranes staining in tumor cells $(3+)$. $\times 10$.

2 years from completion of therapy. All patients with metastatic disease (5/5 patients) responded to treatment with $\mathrm{TCH}$ [11]. Based on the data from this paper, our patient received adjuvant treatment.

There are not enough data from clinical trials about the use of adjuvant treatment in SDC. In a retrospective cohort study, Van Boxtel et al. [12] described the role of adjuvant androgen deprivation therapy (ADT) in patients with poor-risk androgen receptor-positive SDC. This study showed a significantly longer disease-free survival in patients who received ADT compared to the control group. A study by Soo Lee et al. [13] published in February of 2020 concluded that surgery, when followed by radiotherapy, had an effect on local control but not on distant control of the disease. Data from a retrospective cohort study reported a similar conclusion that radiotherapy is useful in local control especially in stage T4 disease. This study also showed that stages N2-3, lymph node involvement levels IV and V, more than eight positive lymph nodes, and extranodal involvement are all negative prognostic factors for overall survival [14]. 
Osborn et al. [15] analyzed treatment and outcome data of 496 patients in a large population based trial. This study showed that there are no adjuvant treatment options that impact the overall survival.

The consensus regarding the use of adjuvant chemotherapy does not exist. In NCCN guidelines, SDC is not listed as a separate entity. We should treat these patients based on the molecular characteristics of the tumors.

Based on all the data that have been presented before, the conclusion is that we need new treatment modalities to improve the outcome of this aggressive disease.

\section{Statement of Ethics}

The subject has given written informed consent to publish her case including publication of images.

\section{Conflict of Interest Statement}

The authors have no conflicts of interest to declare.

\section{Funding Sources}

No financial support was used for this case report.

\section{Author Contributions}

Jelena Berendika, Saša Jungić, and Biljana Tubić searched the literature and wrote the manuscript. Gordan Nikić edited the manuscript. Gordana Kecman-Malčić and Ivanka Rakita supervised the patient treatment. Božana Babić did the pathology report. Zdenka Gojković and Milka Vještica were included in the patient treatment and care. All authors have made significant contributions to the manuscript and have reviewed it before submission. All authors have confirmed that the manuscript is not under consideration for review at any other journal. All authors have read and approved the final manuscript.

\section{References}

1 Brandwein-Gensler MS, Skálová A, Nagao T. Salivary duct carcinoma. In: Barnes EL, Eveson JW, Reichart P, Sidransky D, editors. Chapter 5, Tumours of the Salivary Glands. World Health Organization Classification of Tumours. Pathology and Genetics of Head and Neck Tumours. Lyon: IARC Press; 2005. p 236-7.

2 Glisson B, Colevas AD, Haddad R, Krane J, El-Naggar A, Kies M, et al. HER2 expression in salivary gland carcinomas: Dependence on histological subtype. Clin Cancer Res. 2004;10(3):944-6.

3 Skálová A, Stárek I, Vanecek T, Kucerová V, Plank L, Szépe P, et al. Expression of HER-2/neu gene and protein in salivary duct carcinomas of parotid gland as revealed by fluorescence in situ hybridization and immunohistochemistry. Histopathology. 2003;42:348-56.

4 Johnson CJ, Barry MB, Vasef MA, Deyoung BR. HER-2/neu expression in salivary duct carcinoma: an immunohistochemical and chromogenic in situ hybridization study. Appl Immunohistochem Mol Morphol. 2008; 16(1):54-8.

5 Di Palma S, Simpson RH, Marchiò C, Skálová A, Ungari M, Sandison A, et al. Salivary duct carcinomas can be classified into luminal androgen receptor-positive, HER2 and basal-like phenotypes. Histopathology. 2012; 61(4):629-43.

\section{Karger'₹}


6 Williams MD, Roberts DB, Kies MS, Mao L, Weber RS, El-Naggar AK. Genetic and expression analysis of HER-2 and EGFR genes in salivary duct carcinoma: empirical and therapeuticsignificance. Clin Cancer Res. 2010;16: 2266-74.

7 Williams MD, Roberts D, Blumenschein GR Jr, Temam S, Kies MS, Rosenthal DI, et al. Differential expression of hormonal and growth factor receptors in salivary duct carcinomas: biologic significance and potential role in therapeutic stratification of patients. Am J Surg Pathol. 2007;31(11):1645-52.

8 Boon E, Bel M, van Boxtel W, van der Graaf WTA, van Es RJJ, Eerenstein SEJ, et al. A clinicopathological study and prognostic factor analysis of 177 salivary duct carcinoma patients from The Netherlands. Int J Cancer. 2018 Aug 15;143(4):758.

9 Takase S, Kano S, Tada Y, Kawakita D, Shimura T, Hirai H, et al. Biomarker immunoprofile in salivary duct carcinomas: clinicopathological and prognostic implications with evaluation of the revised classification. Oncotarget. 2017;8(35):59023.

10 Jaehne M, Roeser K, Jaekel T, Schepers JD, Albert N, Löning T. Clinical and immunohistologic typing of salivary duct carcinoma: a report of 50 cases. Cancer. 2005 Jun 15;103(12):2526-33.

11 Limaye SA, Posner MR, Krane JF, Fonfria M, Lorch JH, Dillon DA, et al. Trastuzumab for the treatment of salivary duct carcinoma. Oncologist. 2013;18(3):294-300.

12 van Boxtel W, Locati LD, van Engen-van Grunsven ACH, Bergamini C, Jonker MA, Fiets E, et al., PALGA Group. Adjuvant androgen deprivation therapy for poor-risk, androgen receptor-positive salivary duct carcinoma. Eur J Cancer. 2019 Mar;110:62-70.

13 Lee DS, Lee CG, Keum KC, Chung SY, Kim T, Wu HG, et al. Treatment outcomes of patients with salivary duct carcinoma undergoing surgery and postoperative radiotherapy. Acta Oncol. 2020 May;59(5):565-8.

14 Qian K, Di L, Guo K, Zheng X, Ji Q, Wang Z. Cervical lymph node metastatic status and adjuvant therapy predict the prognosis of salivary duct carcinoma. J Oral Maxillofac Surg. 2018 Jul;76(7):1578-86.

15 Osborn V, Givi B, Lee A, Sheth N, Roden D, Schwartz D, et al. Characterization, treatment and outcomes of salivary ductal carcinoma using the National Cancer Database. Oral Oncol. 2017 Aug;71:41-6. 